\title{
Assessing Supplier Sustainability Using the Analytic Hierarchy Process
}

\author{
Maria-Jose Verdecho, Raul Rodriguez-Rodriguez, and Juan-Jose Alfaro-Saiz \\ Department of Business Organization, \\ CIGIP (Research Centre on Production Management and Engineering), \\ Universitat Politècnica de València, Camino de Vera, s/n, 46022, Valencia, Spain \\ mverdecho@cigip.upv.es
}

\begin{abstract}
Supplier assessment is a relevant decision-making process that aims at monitoring the progress of suppliers in relevant performance aspects and, if results are worse than expected, establishing action plans to improve performance. The works developed for assessing supplier sustainability usually lack of proper structure to monitor supplier sustainability and mechanisms to weight and consolidate performance data into a global evaluation that allows deciding if the supplier is achieving its sustainability goals up to a proper degree. This paper introduces a methodology that fills this research gap and shows a case study in the automotive sector.
\end{abstract}

Keywords: collaborative enterprise networks, sustainability, performance, supplier assessment.

\section{Introduction}

Supplier assessment is a relevant decision-making process that enterprises must deal with. This process may comprise not only the initial stage, the supplier search and selection, but also the monitoring of the supplier performance evolution in the long term. The idea is to monitor the progress of suppliers in relevant performance aspects and, if results are worse than expected, it is possible to obtain the feedback in order to establish action plans to improve performance.

In a collaborative environment, there is a need to integrate the multiple linked processes of the supply chain/enterprise network in order to provide a sound execution of the activities that aid to achieve the strategic goals. In this context, assessing suppliers in key performance aspects for the enterprise network possesses a high value as any improvement in the performance of the supplier will positively impact on the performance of the network.

Achieving sustainability is a major issue for any collaborative enterprise network. Sustainability comprises several dimensions. The three sustainability dimensions, known as the triple-bottom line, are economic, environmental and social dimensions. However, other business dimensions should be considered when the purpose is to analyze the sustainability of suppliers that are to compete within collaborative enterprise networks, due to their specific nature. Such dimensions include aspects of 
managing collaboration relationships. This is an important characteristic as many enterprises have engaged in collaborative relationships despite the fact that proper understanding of collaboration implications is often overlooked causing collaborative relationships to fail. Then, the assessment of a supplier should include not only the evaluation of the sustainability dimensions but also the evaluation of the quality of the collaboration relationship. From a methodological point of view, it can be said that reducing all these dimensions into a single unit of assessment can be an issue. In fact, all these dimensions involve qualitative and quantitative factors so that the problem of assessing supplier sustainability can be defined as a multi-criteria decision problem. Specifically, this work uses the Analytic Hierarchy Process (AHP) multi-criteria method.

This paper proposes an AHP novel methodology for assessing the sustainability of suppliers that participate within collaborative enterprise networks considering four dimensions (three sustainability dimensions as well as collaboration relationship management dimension). With this tool, enterprises that are collaborating will have a tool to assess the most sustainable suppliers aligned with their own strategy and operations enhancing the supplier assessment process as well as their competitiveness in long term. The structure of this paper is as follows. First, a literature review of multi-criteria decision analysis methods applied for supplier assessment is presented focusing attention on the Analytic Hierarchy Process (AHP) method. Then, the multicriteria methodology to assess supplier sustainability is described. After that, a case study showing the application of the approach within the automotive sector is presented. Finally, conclusions are exposed.

\section{Background}

Several methods have been proposed for solving the supplier assessment/selection problem such as vendor profile analysis (VPA), multi-objective programming (MOP), linear programming (LP), fuzzy set theory (FS), data envelopment analysis (DEA), analytic hierarchy process (AHP), genetic algorithm (GA), simple multi-attribute rating technique (SMART) as well as their hybrid approaches. The importance of this problem has been acknowledged in the literature and there are at least four journal articles reviewing the literature regarding supplier evaluation and selection models [1-4].

Assessment of potential suppliers involves both tangible and intangible criteria. This is because assessments of suppliers should not only consider quantitative performance data but also some other criteria that are critical for successful partnerships and are not directly quantifiable, e.g. trust and commitment [5]. Therefore, the AHP method developed by Saaty [6] is a useful method to select suppliers as it deals with both types of criteria. In addition, AHP aims at integrating different measures into a single overall score for ranking decision alternatives [7].

The AHP method has been previously used for supplier assessment under a wide variety of applications [8]. In [9], it is presented an integrated AHP and linear programming method for choosing the best suppliers and placing the optimum order quantities among them. In [10], it is proposed four different vendor assessment systems (VSSs) depending on the time frame (short-term versus long-term) and the content (logistic versus strategic) of the co-operative customer/supplier relationships 
using an AHP framework. In [11], it is proposed an AHP model for supplier assessment based on four groups of criteria: product development capability, manufacturing capability, quality capability, and cost and delivery. In [12], it is applied AHP in the field of project management to assess the best contractor to perform the project based on six criteria: experience, financial stability, quality performance, manpower resources, equipment resources, and current workload. In [13], a multi-criteria group decision making model for supplier ranking based on AHP is developed by combining group member's preferences into one consensus ranking. The criteria used to rate suppliers are quality, delivery, price, technical capability, financial position, past performance attitude, facilities, flexibility and service. In [14], an AHP model to structure SCOR (Supply Chain Operations Reference) model metrics to evaluate overall supplier efficiency is proposed. In [15], it is developed a model for supplier selection process using AHP. In [16], a multi-criteria supplier assessment procedure using AHP is presented. The first level criteria used to compare suppliers involve: supplier, product and service criteria. In [17], it is developed an AHP approach for virtual enterprise partner selection using the SCOR model and the AHP method. In [18], it is presented an AHP approach to select global suppliers according to five criteria: cost, quality, service performance, supplier profile and risk factor.

From the literature review, it is observed that there is not a specific model developed for assessing suppliers that integrates sustainability performance (in fact environmental and social dimensions are usually overlooked) as well as the collaboration relationship performance of suppliers. For this reason, the purpose of the remaining of this paper is to present a multi-criteria AHP methodology for supplier assessment that fills this research gap. With this approach, enterprises that are collaborating will have a tool to assess suppliers based not only on common performance data of suppliers (cost, delivery time, quality, etc.) but also on the other two sustainability dimensions (social and environmental dimensions) as well as the collaboration relationship assessment and, therefore, have a tool to improve their competitiveness in the long term.

\section{The AHP Supplier Sustainability Assessment Methodology}

The methodology is composed of seven phases (see Fig. 1). In the phase 1, the performance elements are defined in four perspectives (business/economic, environmental, social, and collaboration perspectives). It has to be noted that the business/economic perspective does not only cover the strictly economic aspects but also the rest of business ones as performed by [19]. In the phase 2, the AHP method is applied to build a model. The AHP method structures the decision problem in a hierarchy of levels. These levels are linked by unidirectional dependence relationships. In the upper level of the hierarchy, it is defined the ultimate goal of the decision problem. Then, the criteria that contribute to achieve the goal stand in the second level. Then, various intermediate levels may be modelled to represent different levels of sub-criteria. Finally, in the last level, the decision alternatives are established. The AHP method provides relative weights to each element within a level depending on its contribution to an element linked to it that is located on the 
immediate upper level. In our case, as we use the AHP model to obtain the weights of the performance attributes, we will have three levels (see Fig. 2): ultimate goal (supplier sustainability assessment), perspectives (criteria), and performance attributes (alternatives).

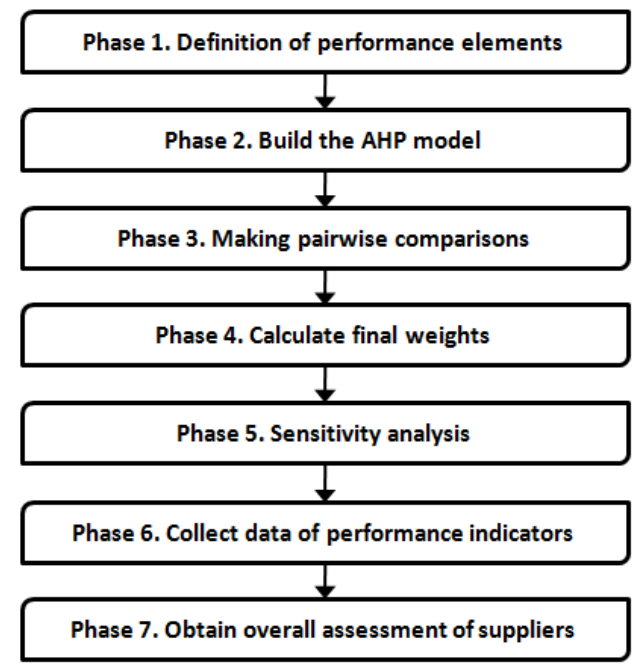

Fig. 1. Methodology phases

In the phase 3, following the application of AHP, pairwise comparisons are made within each level using the fundamental scale of Saaty [6], and the local priorities of the compared elements (priority vector) are calculated. Then, the final weights for the alternatives are calculated (phase 4). For that purpose, priorities of attributes are combined together with the sets of priorities of the performance perspectives.

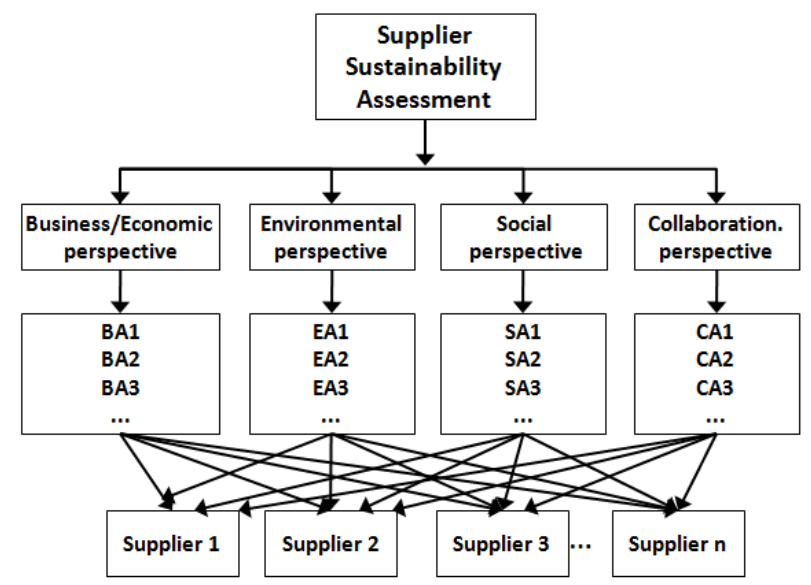

Fig. 2. AHP model for supplier sustainability assessment 
Then, in phase 5 , it is performed a sensitive analysis to check how changes in the local weights of one of the perspectives or attributes affect the final priorities previously obtained. The purpose of this phase is to verify that the solution obtained is robust enough. In case that the solution is not robust, it is needed to go back into the phase 3 to analyze the pairwise comparison matrices obtained. In phase 6 , the data regarding the key performance indicators (KPI) is collected. Finally, in phase 7, it is obtained the overall performance evaluation by multiplying the priority of every performance attribute (given by the normalized priority) and the value reached in its corresponding key performance indicator. This overall performance evaluation has to be contrasted with a value defined as goal, if any, that will represent the degree of sustainability of suppliers to be reached (defined as a percentage of achievement).

\section{Case Study}

The methodology has been applied to the assessment of four suppliers of a multinational first tier supplier that supplies automotive parts to major OEMs. The four suppliers have been working with the enterprise for some years. The Purchase manager, Engineering manager and Quality manager were the decision-makers in the development of the methodology.

The first phase of the methodology consists of the definition of the performance elements for the four perspectives: business, environmental, social and collaboration perspectives. In this activity, managing directors have to reach an agreement on the main attributes to assess the suppliers. These attributes have to be in coherence with the strategic aspects that are followed by the enterprise and the collaborative enterprise network. Table 1 shows the performance elements (attributes and corresponding KPIs) defined for the business, environmental, social and collaboration perspectives. It consists of seventeen attributes and KPIs. For example, the first Business Attribute (BA1) is Cost and the performance indicator defined to measure it is the "compliance with sectoral price behaviour' which is a parameter that translates the price offered by the supplier into a range [1-100] that specifies the price level of that specific supplier. The range [1-100] is established to homogenize the price of different types of products into a single scale, meaning $1=$ more expensive and 100=less expensive. Then, a supplier with a price of 50 means that that supplier offers an average price compared to its competitors. If the price is lower than its competitors, then the decision-makers will rate the supplier from 51 to 100. If the price is more expensive, then, the decision-makers will rate the supplier from 1 to 49. Among the measures defined, some of them have been translated into a similar scale to homogenize the assessments while other KPIs are directly measured such as $\mathrm{KPI} 3=\%$ of parts delivered on time.

It took two meetings of 1.5 hours, what seems reasonable, to complete the list of attributes and KPIs for the four perspectives. During these meetings, a short definition of each attribute was obtained by consensus of the experts to be sure they understand the same concept. For that purpose, definitions for every attribute were provided from the literature. It has to be noted that qualitative attributes, e.g. trust and commitment, are evaluated as 'perceived trust' and 'perceived commitment' by the group of decision-makers. 
Table 1. Performance elements for assessing supplier sustainability

\begin{tabular}{lll}
\hline Perspect. & \multicolumn{1}{c}{ Attributes } & \multicolumn{1}{c}{ KPIs } \\
\hline Business & BA1 Cost & KPI1 = compliance with sectoral price behavior. \\
& BA2 Quality & KPI2 = conformance quality \\
& BA3 Delivery time & KPI3 = \% parts delivered on time \\
& BA4 Product development time & KPI4 = time to market \\
& BA5 Flexibility & KPI5 = product-volume changes \\
& BA6 Innovation & KPI6 = Technology development \\
\hline Environm & EA1 Process controls & KPI7 = implementation of process controls \\
ental & EA2 Pollution prevention & KPI8 = product components and design \\
& EA3 Environmental & KPI9 = ISO 14 000 certification \\
& Management & \\
& EA4 Supplier Environmental & KPI10 = ISO 14 000 supplier's certification \\
& Management & \\
& EA5 Environmental practices & KPI1 =environmental activities \\
\hline Social & SA1 Employment practices & KPI12 = training programs \\
& SA2 Health \& safety (H\&S) & KPI13 = H\&S incidents \\
& problems & \\
& SA3 H\&S implementation & KPI14 = H\&S practices \\
& culture & \\
\hline Collaborat & CA1 Trust & KPI15 = Level of trust \\
ion & CA2 Commitment & KPI16 = Level of commitment \\
& CA3 Information shared & KPI 17 = Level of information shared \\
\hline
\end{tabular}

After building the AHP model and making the pairwise comparison matrices, in the phase 4 , the weights of the attributes are calculated. The most important attributes representing around $68 \%$ of the total weight were: BA1 cost (with normalized weight of 0.14), BA2 Quality (0.13), BA3 Delivery time (0.10), CA1 Trust (0.09), CA3 Information shared (0.08), EA1 Process controls (0.07), and SA3 H\&S problems (0.06). It is important to note that the critical attributes belong to all performance perspectives but the importance of the perspectives differ, being the business perspective the most relevant followed by the environmental and the collaboration perspectives. In the phase 6 , the data of the KPIs is collected for all four suppliers. Table 2 and 3 show the assessments of the business and collaboration perspectives of supplier 1. Finally, in phase 7 , it is obtained the overall assessment of all four suppliers. The analysis provided that supplier 2 ( $80 \%$ of achievement) was the one that reached highest degree of sustainability followed by supplier 1 (77\% of achievement) and supplier $4(72 \%)$. For the decision makers, values of overall sustainability below $70 \%$ mean a low level of sustainability. That is the case of supplier 3 that will need to improve considerably its ratings performance in some of the most relevant attributes (cost, delivery time, and information shared) if they desire to be kept in the supplier base. For those KPIs that have not reached the expected results, actions plans are to be developed which allow improving the current values. In general, sustainability performance has to be improved in all four suppliers in different attributes. This fact can be seen as an expected result as this is the first time in adopting and assessing the sustainability using this methodology and, indeed, this is the main purpose of its application: to be able to provide the key attributes that suppliers have to be focused in order to improve their sustainability. The enterprise 
has requested suppliers the definition of a global action plan as well as reassessment in one year to analyze the evolution of all four suppliers after implementing these action plans. It has to be noted that decision makers filled a questionnaire to assess their satisfaction where they agree with the approach and the results obtained.

Table 2. Assessment of business perspective of supplier 1

\begin{tabular}{|c|c|c|c|c|}
\hline Perspect. & Attributes & Weight & KPIs & KPI value \\
\hline \multirow[t]{6}{*}{ Business } & BA1 Cost & 0,14 & $\begin{array}{l}\text { KPI1 = compliance with sectoral } \\
\text { price behavior. }\end{array}$ & 70 \\
\hline & BA2 Quality & 0,13 & $\mathrm{KPI} 2$ = conformance quality & 80 \\
\hline & $\begin{array}{l}\text { BA3 Delivery } \\
\text { time }\end{array}$ & 0,1 & $\mathrm{KPI} 3=\%$ parts delivered on time & 92 \\
\hline & $\begin{array}{l}\text { BA4 Product } \\
\text { development time }\end{array}$ & 0,05 & $\mathrm{KPI} 4=$ time to market & 90 \\
\hline & BA5 Flexibility & 0,04 & KPI5 = product-volume changes & 70 \\
\hline & BA6 Innovation & 0,05 & KPI6 $=$ Technology development & 60 \\
\hline
\end{tabular}

Table 3. Assessment of collaboration perspective of supplier 1

\begin{tabular}{|c|c|c|c|c|}
\hline Perspect. & Attributes & Weight & KPIs & KPI value \\
\hline \multirow[t]{3}{*}{ Collaboration } & CA1 Trust & 0,09 & KPI15 = Level of trust & 80 \\
\hline & CA2 Commitment & 0,04 & $\begin{array}{l}\text { KPI16 = Level of } \\
\text { commitment }\end{array}$ & 60 \\
\hline & $\begin{array}{l}\text { CA3 Information } \\
\text { shared }\end{array}$ & 0,08 & $\begin{array}{l}\text { KPI } 17=\text { Level of } \\
\text { information shared. }\end{array}$ & 80 \\
\hline
\end{tabular}

\section{Conclusions}

In the recent years, many works have been developed for assessing supplier performance but usually they lack of proper structure to monitor supplier sustainability and mechanisms to weight and consolidate performance data into a global evaluation that allows deciding if the supplier is achieving its sustainability goals up to a proper degree. This paper has introduced a multi-criteria performance methodology that aims to fill this research gap. In addition, the paper has described a case study of an enterprise assessing four suppliers belonging to the automotive sector giving the main features in the development of the application of the methodology. Further research work will be focused on three main aspects. The first research line is to validate this methodology in other case studies of different characteristics and other sectors (for that purpose, a questionnaire will be completed by the experts to assess if they are satisfied with the methodology and the results obtained as was done in this first pilot). The second research line is to deploy further the connection between the methodology developed to assess suppliers and the performance measurement framework for the collaborative enterprise network and the individual enterprises 
performance measurement framework.Finally, the third research line is to develop similar multi-criteria methodologies using other multi-criteria methods in order to contrast the results obtained.

Acknowledgments. This work has been developed within the research project called "Integration of the sustainability indicators within industrial supply chains strategy by applying mathematical techniques (SP20120890)" funded by the Universitat Politècnica de València.

\section{References}

1. Weber, C.A., Current, J.R., Benton, W.C.: Vendor selection criteria and methods. European J. of Operational Research 50(1), 2-18 (1991)

2. Degraeve, Z., Labro, E., Roodhooft, F.: An evaluation of supplier selection methods from a total cost of ownership perspective. European J. of Operational Research 125(1), 34-58 (2000)

3. De Boer, L., Labro, E., Morlacchi, P.: A review of methods supporting supplier selection. European Journal of Purchasing and Supply Management 7(2), 75-89 (2001)

4. Ho, W., Xu, X., Dey, P.K.: Multi-criteria decision making approaches for supplier evaluation and selection: A literature review. European J. of Operational Research 202, 16-24 (2010)

5. Mohr, J., Spekman, R.: Characteristics of partnership success: Partnership attributes, communication. Strategic Management Journal 15(2), 135-152 (1994)

6. Saaty, T.L.: The Analytic Hierarchy Process. McGraw-Hill, New York (1980)

7. Rangone, A.: An analytical hierarchy process framework for comparing the overall performance of manufacturing departments. International Journal of Operations \& Production Management 16(8), 104-119 (1996)

8. Perçin, S.: An application of the integrated AHP-PGP model in supplier selection. Measuring Business Excellence 10(4), 34-49 (2006)

9. Ghodsypour, S.H., O’Brien, C.: A decision support system for supplier selection using an integrated analytic hierarchy process and linear programming. International Journal of Production Economics, 56-57, 199-212 (1998)

10. Masella, C., Rangone, A.: A contigent approach to the design of vendor selection systems for different types of co-operative customer/ supplier relationships. International Journal of Operations \& Production Management 20(1), 70-84 (2000)

11. Akarte, M.M., Surendra, N.V., Ravi, B., Rangaraj, N.: Web based casting supplier evaluation using analytical hierarchy process. J. Operational Research Society 52, 511-522 (2001)

12. Al-Harbi, K.M.: Application of AHP in project management. I.J. Project Management 19(4), 19-27 (2001)

13. Muralidharan, C., Anantharaman, S., Deshmukh, S.G.: A Multi-Criteria Group Decision making Model for Supplier Rating. The Journal of Supply Chain Management: A Global Review of Purchasing and Supply, 22-33 (November 2002)

14. Huan, S.H., Sheoran, S.K., Wang, G.: A review and analysis of supply chain operations reference (SCOR) model. Supply Chain Management: An International Journal 9(9), $23-$ 29 (2004)

15. Chan, F.T.S.: Interactive selection model for supplier selection process: an analytical hierarchy process approach. Int Journal of Production Research 41(15), 3549-3579 (2003) 
16. Kahraman, C., Cebeci, U., Ulukan, Z.: Multi-criteria supplier selection using fuzzy AHP. Logistics Information Management 16(6), 382-394 (2003)

17. Bittencourt, F., Rabelo, R.J.: A systematic approach for VE partners selection using the SCOR model and the AHP method. In: Camarihna-Matos, L., Afsarmanesh, H. (eds.) Collaborative Networks and their Breeding Environments. IFIP, vol. 186, pp. 99-108. Springer, Boston (2005)

18. Chan, F.T.S., Kumar, N.: Global supplier development considering risk factors using fuzzy extended AHP-based approach. Omega 35, 417-431 (2007)

19. Bai, C., Sarkis, J.: Integrating sustainability into supplier selection with grey system and rough set methodologies. Int. J. Production Economics. 124, 252-264 (2010) 